\title{
Recovering $\mathrm{Y}$ and Eu from Waste Phosphors Using Chlorination Roasting-Water Leaching Process
}

\author{
Mingming Yu ${ }^{1}$, Shuya Pang ${ }^{1}$, Guangjun Mei ${ }^{1,2, *}$ and Xiaodong Chen ${ }^{1}$ \\ 1 School of Resources and Environmental Engineering, Wuhan University of Technology, \\ Wuhan 430070, China; ymm1990@whut.edu.cn (M.Y.); chennei1990@whut.edu.cn (S.P.); \\ xdchen@whut.edu.cn (X.C.) \\ 2 School of Chemistry and Life Science, Hubei University of Education, Wuhan 430205, China \\ * Correspondence: meiguangjun@aliyun.com
}

Academic Editor: Massimiliano Zanin

Received: 8 July 2016; Accepted: 13 October 2016; Published: 19 October 2016

\begin{abstract}
Recovering $\mathrm{Y}$ and $\mathrm{Eu}$ from waste phosphors using chlorination roasting followed by a water leaching process was investigated in this study. Firstly, by chlorination roasting and water leaching, $\mathrm{Y}$ and Eu elements present in waste phosphors were efficiently extracted into a leach solution. Secondly, the majority of the impurities in the solution can be removed by adjusting the $\mathrm{pH}$ to 4.5 using a $\mathrm{Na}_{2} \mathrm{~S}$ and $\mathrm{NH}_{3} \cdot \mathrm{H}_{2} \mathrm{O}$ solution. Thirdly, the rare earths can be precipitated afterwards by adding a $\mathrm{H}_{2} \mathrm{C}_{2} \mathrm{O}_{4}$ solution and adjusting the $\mathrm{pH}$ to 2.0. Then rare earth oxides (REOs) can be obtained after calcining at $800{ }^{\circ} \mathrm{C}$ for $1 \mathrm{~h}$. The characterization study of the waste phosphors and the rare earth oxide products was performed by XRD, XRF, and SEM-EDS analysis to determine the phase and morphological features. Influences of the factors, such as roasting temperatures and time, the addition of ammonium chloride on the roasting of waste phosphors, as well as the $\mathrm{pH}$ and the amount of oxalates on the precipitation of $\mathrm{Y}$ and $\mathrm{Eu}$, were investigated. The maximum grade $(99.84 \%)$ of mixed rare earth oxides and recovery rate $(87.35 \%)$ of $Y$ and Eu were obtained at the optimized conditions.
\end{abstract}

Keywords: waste phosphors; chlorination roasting; water leaching; rare earth elements; recycling

\section{Introduction}

The lighting industry has undergone great improvements with the advent of the rare earth phosphors. At the end of the life of fluorescent tubes, these phosphors have usually been discarded as waste products after mercury removal [1]. As waste phosphors have shown an increased environmental burden and pose a significant risk to human health due to the existence of heavy metals, such as mercury and manganese, they have received wide attraction as urban mining resources for extracting rare earth elements (RE), such as yttrium (Y), europium (Eu), cerium (Ce), and terbium (Tb). In 2011, about 4800 million fluorescent lamps were disposed [2], and the value of rare earths contained in the waste phosphors was more than 1600 million dollars. If these rare earth elements can be recycled and reused efficiently, it will reduce the exploitation of primary rare earth minerals and build the circular-utilization industrial chain of abandoned rare earths, which will greatly help improve the efficient utilization of rare earth resources.

Phosphors are a mixture of red phosphors, blue phosphors, and green phosphors, in which red phosphors are rare earth oxides, which can be decomposed by hydrometallurgical processes, and $Y$ and Eu elements presented in red phosphors can be recovered relatively easily. However, the chemical structures of blue and green powders are in spinel structures [3,4], these chemical structures are so stable that they are difficult to destroy with inorganic acids [5]. 
Various pyrometallurgical and hydrometallurgical approaches for recovery of $\mathrm{Y}$ and Eu from waste phosphors have been reported by many researchers [6]. Using two steps of liquid-liquid extraction, waste phosphors can be separated into red, green, and blue phosphors [7]. De Michelis compared different acid leaching systems to study yttrium extraction from waste fluorescent powders, and proved that red phosphors could be dissolved in inorganic acid solution [8], and using a hydrochloric acid with hydrogen peroxide system, red phosphors could be effectively dissolved by leaching [9].

It is well known that too many acids and high amounts of energy are consumed in the above process, and highly corrosion-resistant equipment is required. The drawbacks of such a process limit further applications. Chloride metallurgy is emerging as an alternative process, which has been proven to be more efficient and cheaper for the extraction and used to refine precious, base, and refractory metals $[10,11]$. Up to now, few studies have been conducted to recover rare earth elements from waste phosphors by chlorination roasting, however, this method is particularly well-suited for the recovery of valuable metals in mineral processing. Rare earth elements can be recovered by using ammonium chloride roasting with a fluorine deactivation process [12]. By selective chlorination roasting, the valuable metals can be recovered from a spent nickel-metal hydride battery [13]. Yan et al. extracted lithium from lepidolite using chlorination roasting and water leaching processes [14]. In these processes, $\mathrm{NH}_{4} \mathrm{Cl}$ decomposes into gaseous $\mathrm{HCl}$ under heating, and the produced gaseous $\mathrm{HCl}$ reacts with the rare earth oxide to form a rare earth chloride $\left(\mathrm{RECl}_{3}\right)$, which can be easily leached out of the minerals using water [15]. In this study, the ammonium chloride roasting technique, followed by a water leaching process was applied to the recovery of $Y$ and Eu elements from waste phosphors.

\section{Materials and Methods}

\subsection{Materials}

The waste phosphors used were mercury-free waste phosphors supplied by a Peiyuan Lighting Materials Co., Ltd. (Jiangzhou, China). The composition of the samples was analyzed by X-ray fluorescence (XRF) and the results are shown in Table 1, indicating that the total content of rare earth elements is $22.93 \%$-including $\mathrm{Y}, \mathrm{Eu}, \mathrm{Ce}$, and $\mathrm{Tb}$. Content of $\mathrm{Si}$ is $24.97 \%$ which is much higher than expected for the phosphors, which is probably due to a certain amount of Si from the fluorescent tubes.

Table 1. Chemical composition of actual waste phosphors.

\begin{tabular}{cccc}
\hline Oxides & Content $\mathbf{( w t} \%)$ & Oxides & Content $\mathbf{( w t} \%)$ \\
\hline $\mathrm{Na}_{2} \mathrm{O}$ & 2.89 & $\mathrm{Eu}_{2} \mathrm{O}_{3}$ & 1.60 \\
$\mathrm{MgO}$ & 2.05 & $\mathrm{MnO}$ & 0.11 \\
$\mathrm{Al}_{2} \mathrm{O}_{3}$ & 20.04 & $\mathrm{Fe}_{2} \mathrm{O}_{3}$ & 0.52 \\
$\mathrm{SiO}_{2}$ & 24.97 & $\mathrm{ZnO}$ & 0.04 \\
$\mathrm{SO}_{3}$ & 0.091 & $\mathrm{SrO}$ & 0.67 \\
$\mathrm{CaO}$ & 9.11 & $\mathrm{P}_{2} \mathrm{O}_{5}$ & 7.64 \\
$\mathrm{~K}$ & $\mathrm{Sb}$ & $\mathrm{Sb}_{2} \mathrm{O}_{3}$ & 0.10 \\
$\mathrm{BaO}$ & 1.77 & $\mathrm{PbO}$ & 1.27 \\
$\mathrm{CeO}$ & $\mathrm{Tb}_{4} \mathrm{O}_{7}$ & 1.03 \\
$\mathrm{WO}_{3}$ & 3.54 & $\mathrm{Cl}$ & 0.14 \\
$\mathrm{Y}_{2} \mathrm{O}_{3}$ & 1.48 & Loss on Ignition & 1.91 \\
\hline
\end{tabular}

Figure 1 shows the $\mathrm{X}$-ray diffraction (XRD) analysis of waste phosphors, indicating that the main crystalline phases of samples are $\mathrm{Y}_{2} \mathrm{O}_{3}$ : $\mathrm{Eu}^{3+}$ (red phosphor), $(\mathrm{CeTb}) \mathrm{MgAl}_{11} \mathrm{O}_{19}$ (green phosphor), $\mathrm{BaMgAl}_{10} \mathrm{O}_{17}: \mathrm{Eu}^{2+}$ (blue phosphor), and $\mathrm{SiO}_{2}$ (quartz).

Figure 2 and Table 2 show the Scanning Electron Microscope-Energy Dispersive Spectrometer (SEM-EDS) image of waste phosphors, in which the large granular particles are fragments of fluorescent tubes (Point-4), the elements presented in these particles were mainly Si and O, the bright particles 
were red phosphors (Point-3), the main elements were $\mathrm{Y}$ and $\mathrm{O}$, Point-1 and Point-2 were blue and green phosphors; the main elements were $\mathrm{O}$, $\mathrm{Al}$, etc.

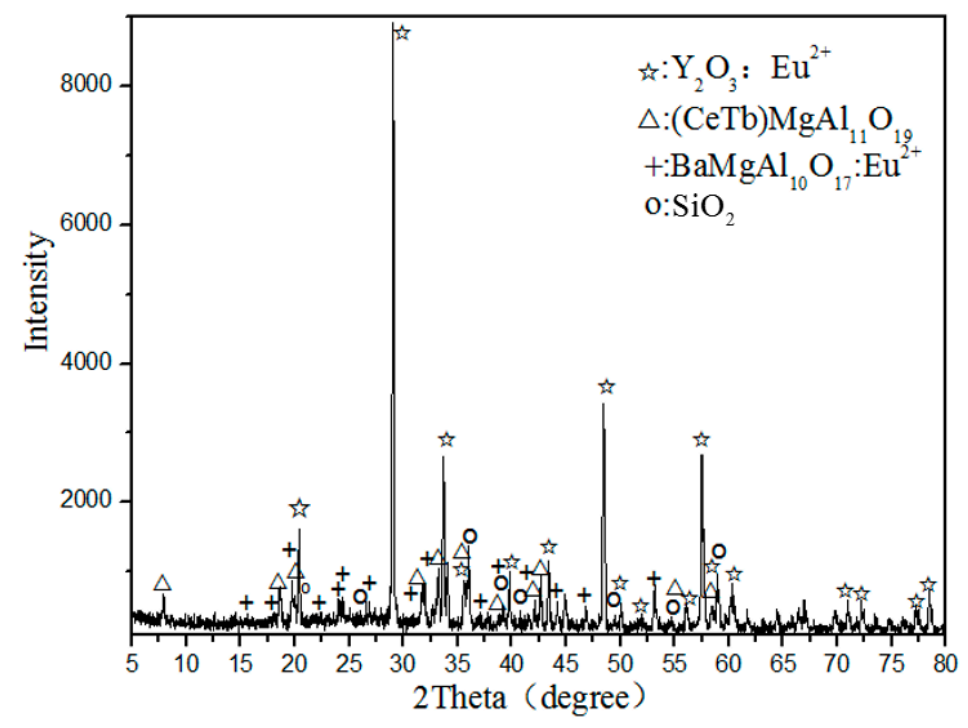

Figure 1. XRD analysis of waste phosphor.
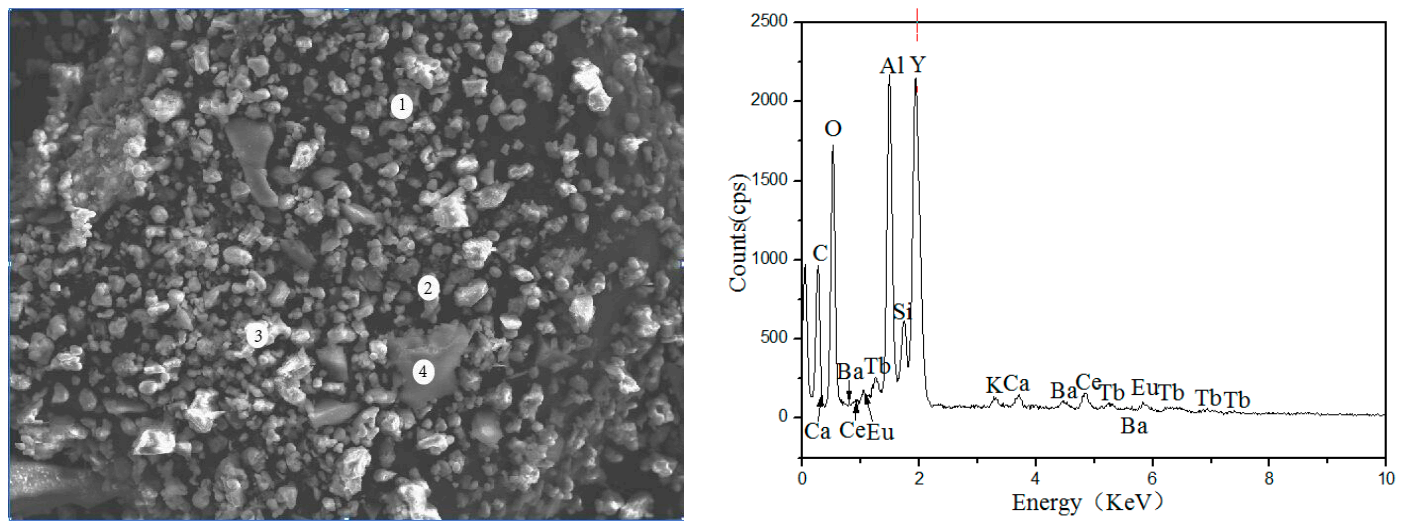

Figure 2. SEM-EDS analysis of waste phosphors.

Table 2. EDS analysis of waste phosphors.

\begin{tabular}{ccccc}
\hline \multirow{2}{*}{ Elements } & \multicolumn{4}{c}{ Content (wt\%) } \\
\cline { 2 - 5 } & Point-1 & Point-2 & Point-3 & Point-4 \\
\hline $\mathrm{O}$ & 38.50 & 44.54 & 31.22 & 44.34 \\
$\mathrm{Mg}$ & 2.63 & 2.06 & 0.37 & 0.54 \\
$\mathrm{Al}$ & 35.05 & 36.21 & 5.09 & 2.71 \\
$\mathrm{Ca}$ & 0.29 & - & 0.74 & 1.10 \\
$\mathrm{Si}$ & 2.35 & 3.99 & - & 26.88 \\
$\mathrm{Y}$ & 3.42 & 8.05 & 57.22 & - \\
$\mathrm{Ba}$ & 12.41 & 5.46 & 1.38 & 1.38 \\
$\mathrm{Ce}$ & - & 4.46 & 0.38 & - \\
$\mathrm{Tb}$ & - & 2.65 & - & - \\
$\mathrm{Eu}$ & 2.66 & 2.62 & 2.79 & - \\
\hline
\end{tabular}




\subsection{Methods}

\subsubsection{Roasting and Leaching of Waste Phosphors}

For each test, $20 \mathrm{~g}$ of waste phosphors were well mixed with ammonium chloride, placed into a crucible, placed over a muffle burner, and heated at $250-500{ }^{\circ} \mathrm{C}$ for $30-120 \mathrm{~min}$. Next, deionized water was carefully added to the crucible with a solid-to-liquid ratio of 1:10. Then, the materials in the crucible were magnetically stirred for $10 \mathrm{~min}$ at $25^{\circ} \mathrm{C}$, and the leach solution was then separated from the residue by filtration using a vacuum pump and a filter. The residue was washed a few times with deionized water and dried in a drying oven, and characterized by XRD and SEM-EDS. The leach solution was analyzed by Inductively Coupled Plasma Optical Emission Spectrometer (ICP-OES) to calculate the leaching rate of $\mathrm{Y}$ and Eu. There is a vent hole in the top of the muffle burner, and the ammonia gas generated in this process escapes via the vent hole, and then is introduced into a container with a diluted hydrochloric acid solution, and converted into an ammonium chloride solution. Such treatment minimizes possible environmental issues and has the potential for possible reuse of the ammonium chloride solution in the process.

\subsubsection{Extraction of Rare Earth Elements}

The $\mathrm{pH}$ of the leach solution was adjusted by continuously adding a $\mathrm{Na}_{2} \mathrm{~S}$ and $\mathrm{NH}_{3} \cdot \mathrm{H}_{2} \mathrm{O}$ solution. With the increasing $\mathrm{pH}$, the impurities can be precipitated gradually. The precipitated product was separated by filtration. The leach solution was added to the oxalate solution to precipitate $\mathrm{Y}$ and $\mathrm{Eu}$ ions, and the $\mathrm{pH}$ values were adjusted by adding $\mathrm{HCl}$ or $\mathrm{NH}_{3} \cdot \mathrm{H}_{2} \mathrm{O}$ solution. The precipitation process lasted for $4 \mathrm{~h}$ at $80^{\circ} \mathrm{C}$, and then the precipitated product was filtered, dried, and roasted at $800{ }^{\circ} \mathrm{C}$ for $2 \mathrm{~h}$, with the final mixed rare earth oxides (REOs) obtained.

\subsection{Reagents and Equipment}

X-ray fluorescence analysis (XRF) was conducted using an AXIOS system (PANalytical. B.V, Co., Ltd., Ea Almelo, The Netherlands), and X-ray diffraction (XRD) analysis was measured with an RU-200B (Rigaku Co., Ltd., Tokyo, Japan). The pH meter used was an HM-40V (TOA Denpa Togyo, Co., Ltd., Tokyo, Japan). Prodigy 7 (Leeman Labs Inc., Hudson, NH, USA) was used to conduct the Inductively Coupled Plasma Optical Emission Spectrometer (ICP-OES) analysis. Scanning Electron Microscope/Energy Dispersive Spectroscopy (SEM-EDS) analysis was carried out on a Zeiss Ultra Plus (Carl Zeiss AG, Oberkochen, Germany). The muffle burner with vent hole was supplied by Guoju Industry, Co., Ltd., Luoyang, China (GWL-1600LB).

As for chlorination roasting-water leaching process, ammonium chloride $\left(\mathrm{NH}_{4} \mathrm{Cl}\right)$ was used as the chlorinating agent, $\mathrm{HCl}$ and $\mathrm{NH}_{3} \cdot \mathrm{H}_{2} \mathrm{O}$ as $\mathrm{pH}$ regulators. All chemicals were first grade reagents and distilled water was used for all solutions.

\section{Results and Discussion}

\subsection{Effect of Roasting Temperatures and Time on the Leaching Rate of $Y$ and Eu}

Thermogravimetric-Differential Scanning calorimeter (TG-DSC) curves of waste phosphors mixed with $\mathrm{NH}_{4} \mathrm{Cl}$ on a mass ratio of 1:4 after chlorination roasting at atmospheric pressure are shown in Figure 3. Two endothermic peaks at 196.7 and $323.7^{\circ} \mathrm{C}$ were observed in the DSC curve. The endothermic peak at $193.1^{\circ} \mathrm{C}$ was due to the release of adsorbed water of $\mathrm{NH}_{4} \mathrm{Cl}$. The endothermic peak at $323.7^{\circ} \mathrm{C}$ was due to the decomposition of the $\mathrm{NH}_{4} \mathrm{Cl}$ shown in Formula (1). During the roasting process, $\mathrm{HCl}$ is in the form of gas, generated from the decomposition of ammonium chloride, and waste phosphors react with $\mathrm{HCl}$ to form rare earth chlorides (Formula (2)). TG and DSC curves indicate that chlorination roasting temperature is an important factor in determining the metal leaching efficiency.

$$
\mathrm{NH}_{4} \mathrm{Cl}=\mathrm{NH}_{3}+\mathrm{HCl}_{(\mathrm{g})}\left(328^{\circ} \mathrm{C}\right)
$$




$$
\mathrm{RE}_{2} \mathrm{O}_{3}+6 \mathrm{HCl}_{(\mathrm{g})}=2 \mathrm{RECl}_{3}+3 \mathrm{H}_{2} \mathrm{O}
$$

The effect of chlorination roasting temperature on the leaching rate of $\mathrm{Y}$ and $\mathrm{Eu}$ from waste phosphors was carried out at a mass ratio of 1:4 (waste phosphors to $\mathrm{NH}_{4} \mathrm{Cl}$ ) for 90 min. Related results are shown in Figure 4. It shows that the $\mathrm{Y}$ and Eu leaching efficiency increases rapidly from a low value at $250{ }^{\circ} \mathrm{C}$ to the maximum at $400{ }^{\circ} \mathrm{C}$. As expected, high temperature promotes the decomposition of waste phosphors. However, above $400{ }^{\circ} \mathrm{C}$, leaching ratios clearly decrease because the reaction shown in Formula (1) becomes vigorous, leading to the significant generation of $\mathrm{HCl}$ into the air, decreasing the amount of $\mathrm{HCl}$ for phosphor decomposition. Moreover, the higher quantity of $\mathrm{HCl}$ generated also causes severe environmental pollution. To decrease energy consumption and avoid air pollution, roasting temperature should be controlled within $400{ }^{\circ} \mathrm{C}$.

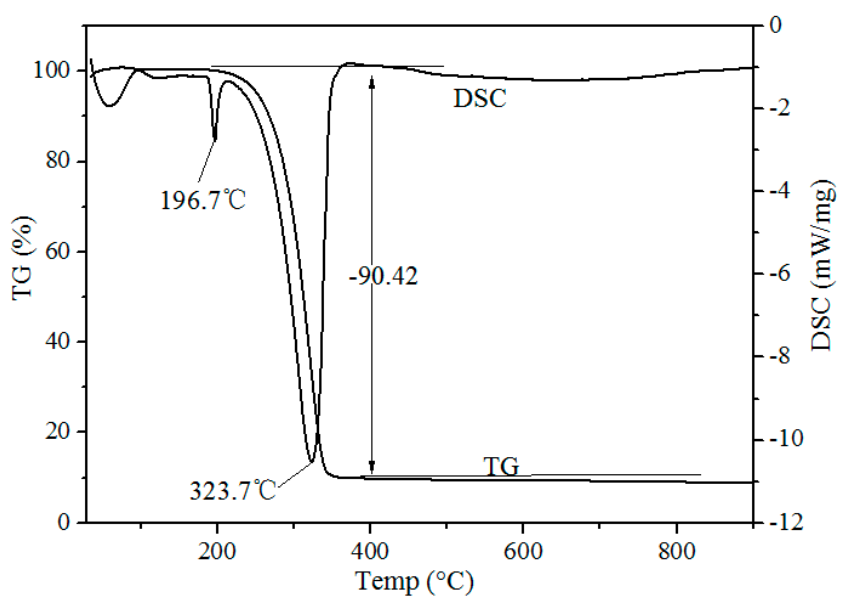

Figure 3. TG-DSC curves of waste phosphors mixed with $\mathrm{NH}_{4} \mathrm{Cl}\left(m(\right.$ ore $\left.): m\left(\mathrm{NH}_{4} \mathrm{Cl}\right)=1: 4\right)$.

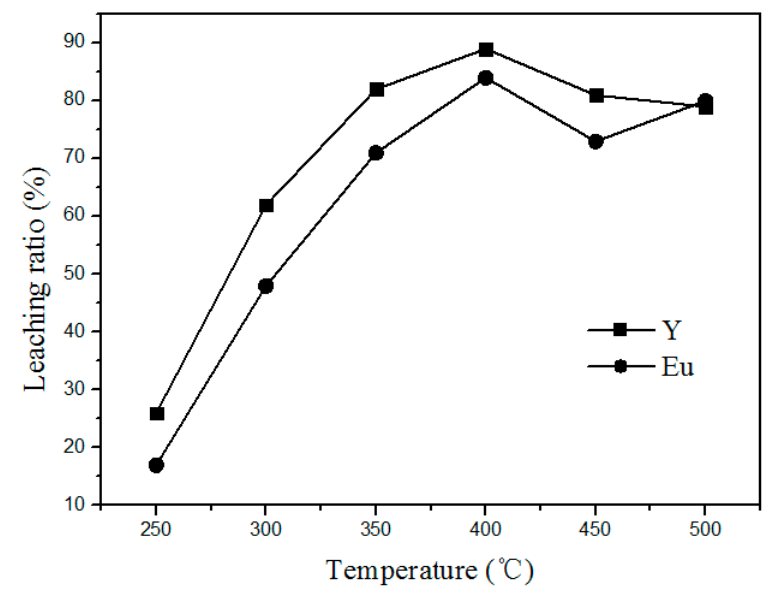

Figure 4. Effect of roasting temperature on the leaching rate of the rare earths.

Additionally, the time of roasting is another important factor that influences the leaching process. Figure 5 shows the variation in the leaching rate of $Y$ and $\mathrm{Eu}$ at different roasting times at $400{ }^{\circ} \mathrm{C}$ and a mass ratio of 1:4 (waste phosphors to $\mathrm{NH}_{4} \mathrm{Cl}$ ). The leaching rate increased with increasing leaching time by $30-90 \mathrm{~min}$. Above $90 \mathrm{~min}$, the variation in the leaching rate is insignificant. Therefore, the optimum time for the leaching process is $90 \mathrm{~min}$. 


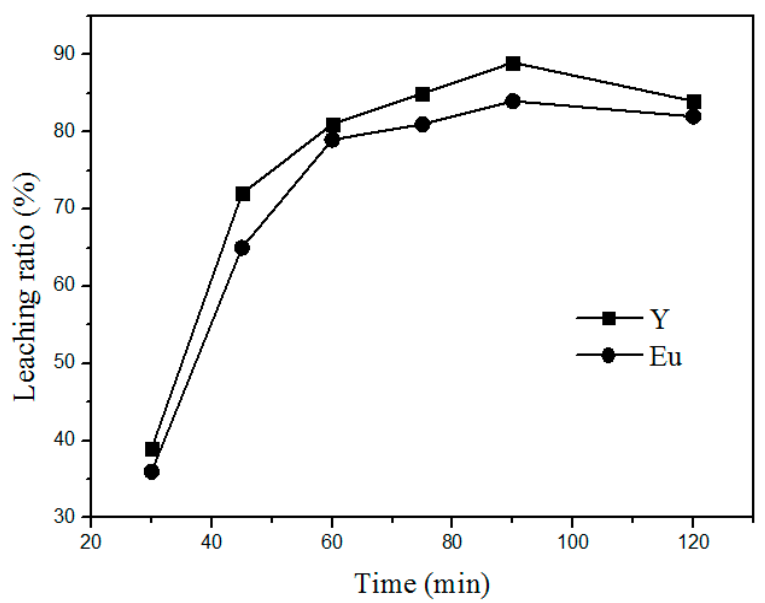

Figure 5. Effect of roasting time on the leaching rate of the rare earths.

\subsection{Effect of Ammonium Chloride Addition}

To achieve complete chloride reactions, the waste phosphors and ammonium chloride have to be well mixed. In addition, to save operating costs and enhance the leaching rate, a suitable amount of ammonium chloride should be added for maximizing the reaction efficiency. Figure 6 shows the relationship between the leaching rate and the amount of ammonium chloride added at $400{ }^{\circ} \mathrm{C}$ for $90 \mathrm{~min}$. The leaching rate increased with the increased addition of ammonium chloride. This is consistent with the roasting reactions as shown in Formulas (1) and (2). However, the leaching rate increased only marginally after the weight ratio of waste phosphors to ammonium chloride reached 1:4. Hence, 1:4 was taken as the optimum mass ratio of waste phosphors to $\mathrm{NH}_{4} \mathrm{Cl}$ for the rest of the study.

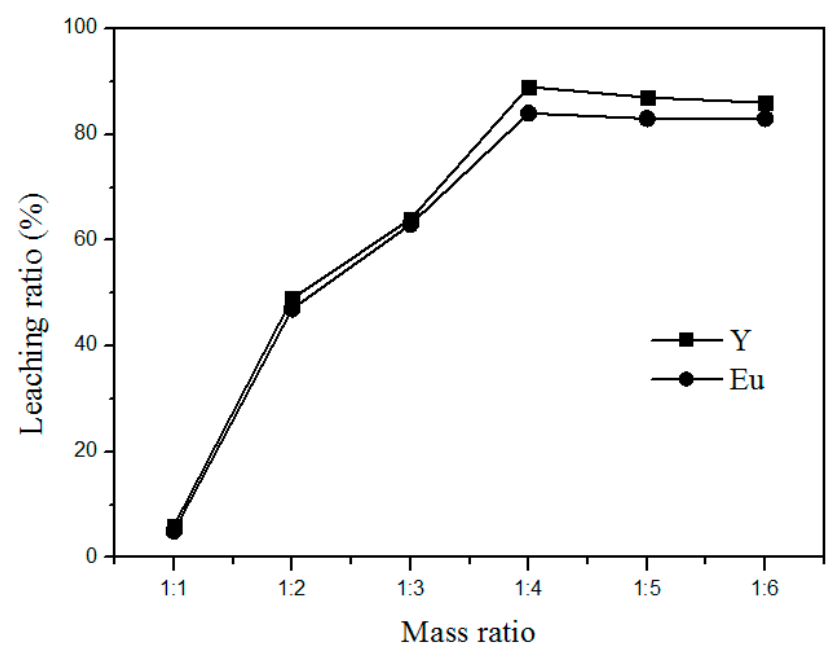

Figure 6. Effect of $\mathrm{NH}_{4} \mathrm{Cl}$ addition on the leaching rate of $\mathrm{Y}$ and Eu.

\subsection{Variation of Phase in the Roasting and Leaching Process}

The SEM-EDS analysis of the leaching residue (Figure 7) shows that the main elements present in the residue are $\mathrm{O}, \mathrm{Si}$, and $\mathrm{Al}$, and the peak of $\mathrm{Y}$ and $\mathrm{Eu}$ disappeared after the water leaching process, indicating that $\mathrm{Y}$ and Eu elements present in the phosphors can be efficiently extracted into the leach solution. 

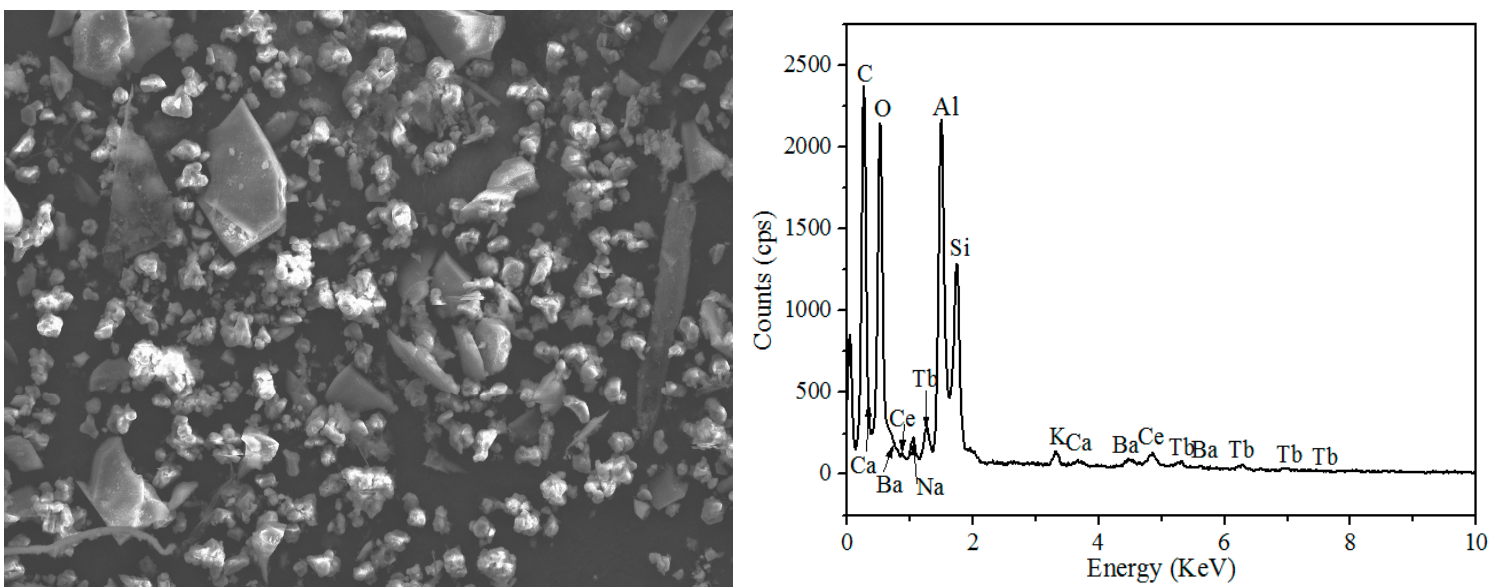

Figure 7. SEM-EDS analysis of the leach residue.

Figure 8a shows the XRD pattern of waste phosphors after roasting at $400{ }^{\circ} \mathrm{C}$. The pattern shows that the main phases transformed to $\mathrm{YCl}_{3},(\mathrm{CeTb}) \mathrm{MgAl}_{11} \mathrm{O}_{19}, \mathrm{BaMgAl}_{10} \mathrm{O}_{17}: \mathrm{Eu}^{2+}$, and $\mathrm{SiO}_{2}$, indicating that the red phosphors $\left(\mathrm{Y}_{2} \mathrm{O}_{3}: \mathrm{Eu}^{3+}\right)$ react with $\mathrm{NH}_{4} \mathrm{Cl}$ and form $\mathrm{RECl}_{3}$ after roasting. The XRD pattern of the leaching residue (Figure $8 b$ ) shows that the main phases were $\mathrm{SiO}_{2},(\mathrm{CeTb}) \mathrm{MgAl}_{11} \mathrm{O}_{19}$, and $\mathrm{BaMgAl}_{10} \mathrm{O}_{17}: \mathrm{Eu}^{2+}$, indicating that $\mathrm{RECl}_{3}$ was leached to the solution. This indicated that red phosphors can be effectively destroyed by chlorination roasting and rare earth elements can become soluble, which can then be easily separated from the insoluble materials, such as $\mathrm{SiO}_{2}$ and blue and green phosphors, by leaching.

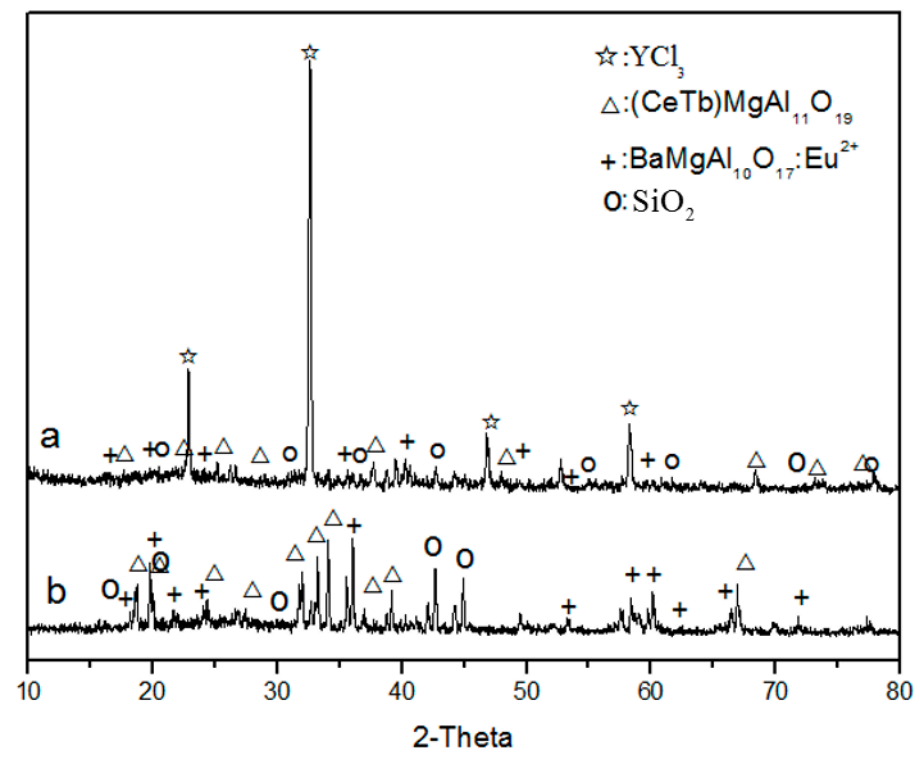

Figure 8. XRD analysis of waste phosphor after roasting (a); and water leaching (b).

\subsection{Separation of Impurities from the Leach Solution}

After leaching, a small amount of impurities are dissolved in the leach solution. Those ions could precipitate after adding oxalates with rare earths and decrease the purity of rare earth products. In order to remove the impurities effectively without precipitating the rare earths, a variety of agents have been tested. The results show that $\mathrm{NH}_{3} \cdot \mathrm{H}_{2} \mathrm{O}, \mathrm{NH}_{4} \mathrm{HCO}_{3}$, and $\mathrm{Na}_{2} \mathrm{~S}$ can remove the impurities effectively. Wherein the effect of $\mathrm{NH}_{4} \mathrm{HCO}_{3}$ was the most effective, but the loss ratio of rare earth was the highest $(40.3 \%)$, and using a $\mathrm{Na}_{2} \mathrm{~S}$ solution the loss ratio of rare earth was the lowest, but it cannot 
remove the impurities effectively (7.2\%). In the quest for more precipitation of impurities and lower loss ratio of rare earth, this study uses a $\mathrm{NH}_{3} \cdot \mathrm{H}_{2} \mathrm{O}$ and $\mathrm{Na}_{2} \mathrm{~S}$ solution to precipitate the impurities.

As shown in Figure 9, the concentration of $\mathrm{Fe}, \mathrm{Al}, \mathrm{Pb}$, and $\mathrm{Zn}$ clearly decreases with increasing $\mathrm{pH}$ because the $\mathrm{Pb}^{2+}$ and $\mathrm{Zn}^{2+}$ were precipitated with $\mathrm{S}^{2-}$, and $\mathrm{Al}^{3+}$ and $\mathrm{Fe}^{3+}$ were hydrolyzed with increasing $\mathrm{pH}$ via the reactions shown in Formulas (3)-(6). The concentrations of $\mathrm{Y}$ and Eu do not decrease until the $\mathrm{pH}$ exceeds 4.50 (Figure 10). The $\mathrm{pH}$ required for the hydrolysis of $\mathrm{Y}$ and Eu is higher than those of $\mathrm{Al}$ and $\mathrm{Fe}$, thus the impurities can be separated by adding a $\mathrm{Na}_{2} \mathrm{~S}$ and $\mathrm{NH}_{3} \cdot \mathrm{H}_{2} \mathrm{O}$ solution to adjust the $\mathrm{pH}$ value to 4.5 .

$$
\begin{gathered}
\mathrm{Pb}^{2+}+\mathrm{S}^{2-}=\mathrm{PbS} \downarrow \\
\mathrm{Zn}^{2+}+\mathrm{S}^{2-}=\mathrm{ZnS} \downarrow \\
\mathrm{Fe}^{3+}+3 \mathrm{OH}^{-}=\mathrm{Fe}(\mathrm{OH})_{3} \downarrow \\
\mathrm{Al}^{3+}+3 \mathrm{OH}^{-}=\mathrm{Al}(\mathrm{OH})_{3} \downarrow
\end{gathered}
$$

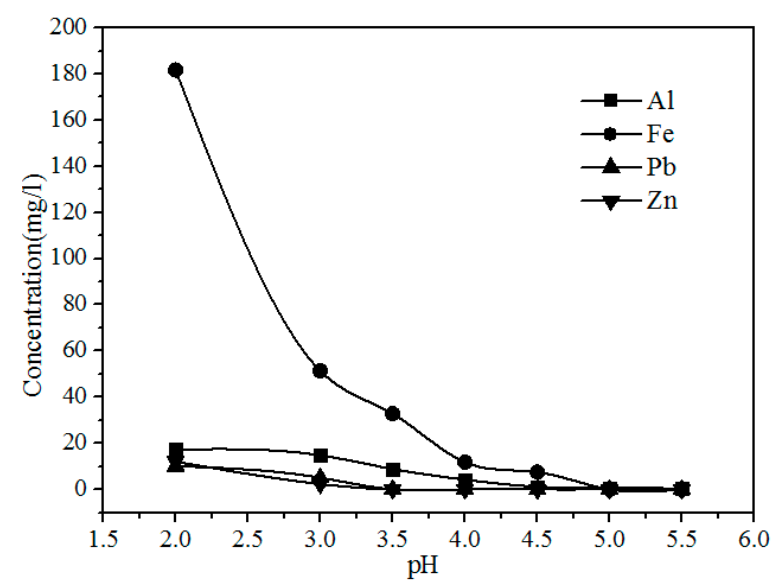

Figure 9. Effect of $\mathrm{pH}$ on the concentration of $\mathrm{Al}, \mathrm{Fe}, \mathrm{Pb}$, and $\mathrm{Fe}$ in the leach solution.

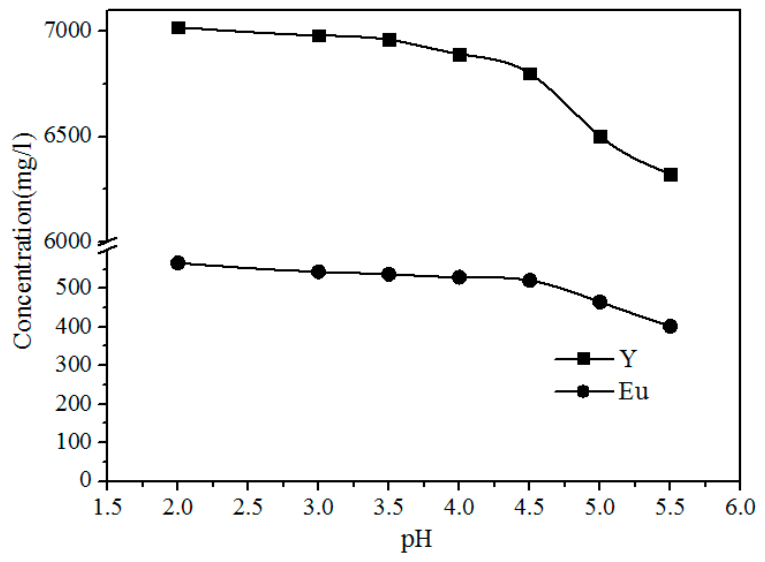

Figure 10. Effect of $\mathrm{pH}$ on the concentration of $\mathrm{Y}$ and $\mathrm{Eu}$ in the leach solution.

\subsection{Extraction of Rare Earth Elements from the Leach Solution}

The leach solution under the optimum conditions was taken for the recovery of rare earth elements by precipitation using an oxalate solution (Formula (7)): 


$$
2 \mathrm{RE}^{3+}+3 \mathrm{H}_{2} \mathrm{C}_{2} \mathrm{O}_{4}+x \mathrm{H}_{2} \mathrm{O}=\mathrm{RE}_{2}\left(\mathrm{C}_{2} \mathrm{O}_{4}\right)_{3} \cdot x \mathrm{H}_{2} \mathrm{O} \downarrow+6 \mathrm{H}^{+}
$$

It should be noted that, based on the precipitation reaction, 6 mols of $\mathrm{H}^{+}$could be generated with the generation of $1 \mathrm{~mol}$ of precipitate, the $\mathrm{pH}$ values of the solution could decrease, and a high concentration of $\mathrm{H}^{+}$can increase the solubility of rare earth precipitation, it is not conducive to the precipitation of rare earths. Therefore, in the process of the precipitation reaction, the amount of oxalates and the $\mathrm{pH}$ values are significant for the precipitation of rare earths.

Figure 11 shows the relationship between the precipitation rate and oxalate addition (the mass ratio of rare earth elements to the oxalate addition) at $\mathrm{pH}$ values of 1.5 . The precipitation rate increased with the increased addition of oxalates, after the mass ratio reaches 1:2.5 the variation in the precipitation rate is insignificant. Hence, the optimum mass ratio chosen was 1:2.5.

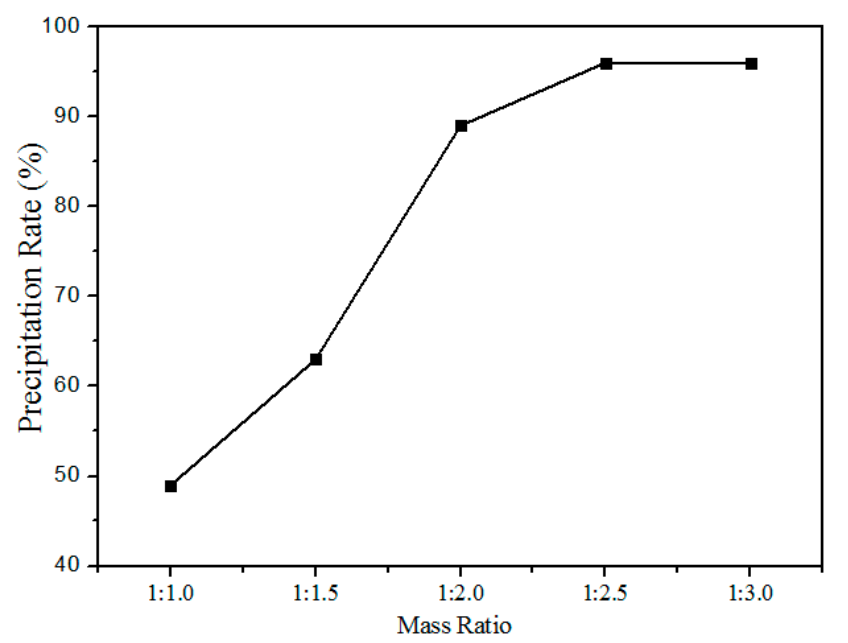

Figure 11. Effect of oxalate addition on the precipitation rate of RE elements.

Figure 12 shows the precipitation ratio of rare earths at different $\mathrm{pH}$ values. It is shown that the precipitation rate of the rare earths increased with increasing $\mathrm{pH}$. Above $\mathrm{pH}$ 2.0, the RE was almost completely precipitated. Therefore, the optimum $\mathrm{pH}$ value is 2.0 .

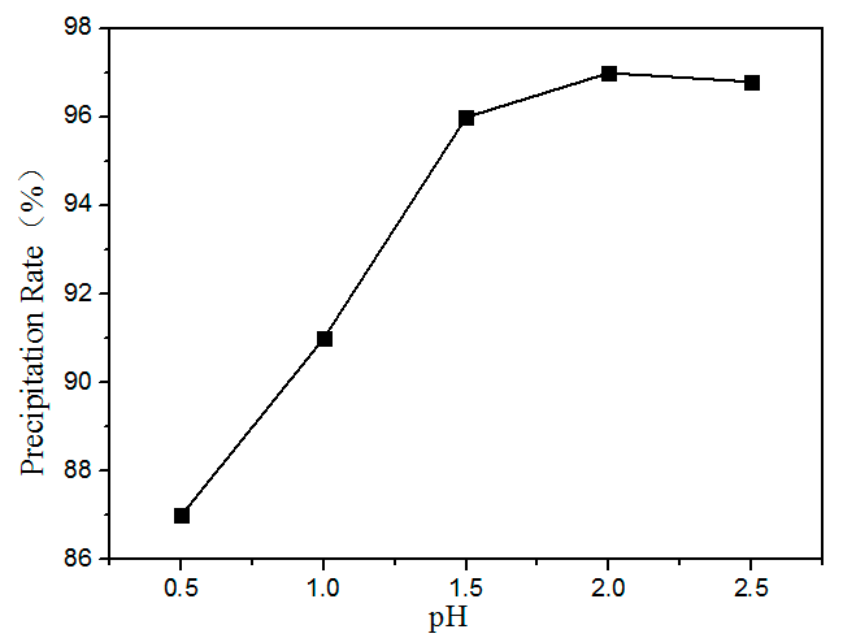

Figure 12. Effect of $\mathrm{pH}$ value on the precipitation ratios of RE elements.

As shown in Figure 13, the product obtained by calcining the oxalate's precipitation of RE has an irregular crystal shape with an average length of $5 \mu \mathrm{m}$. The result of XRD analysis (Figure 14) shows 
that the main crystalline phase of the REOs is $\mathrm{Y}_{2} \mathrm{O}_{3}$ and $\mathrm{Eu}_{2} \mathrm{O}_{3}$. The diffraction peaks of the REOs are sharp without any impurity peaks, indicating that the product was a high purity material of $\mathrm{Y}$ and Eu. The composition of the product is listed in Table 3, indicating the total content of $\mathrm{Y}_{2} \mathrm{O}_{3}$ and $\mathrm{Eu}_{2} \mathrm{O}_{3}$ is $99.84 \%$, and the products can be reused to synthesize red phosphors directly without separating $\mathrm{Y}_{2} \mathrm{O}_{3}$ and $\mathrm{Eu}_{2} \mathrm{O}_{3}$.

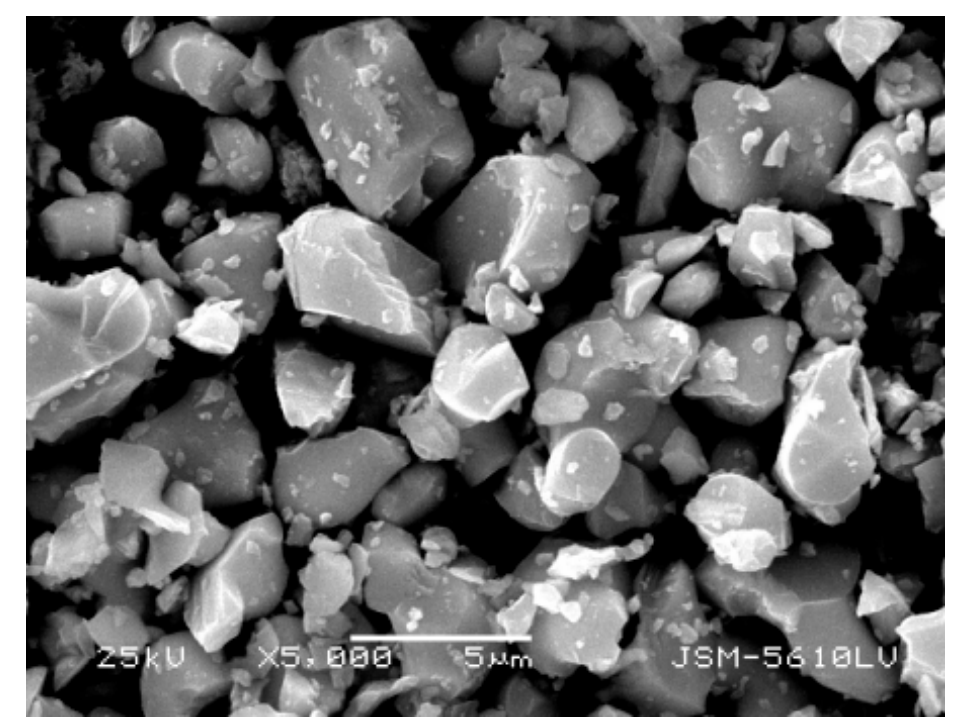

Figure 13. SEM photograph of REOs.

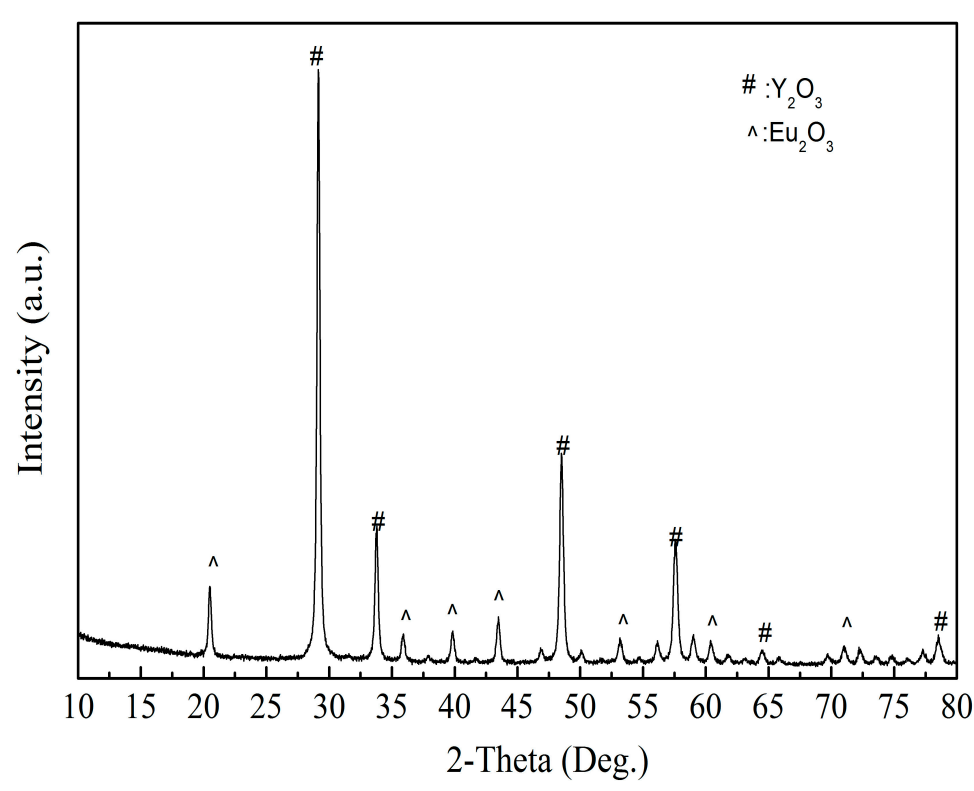

Figure 14. The XRD analysis of REOs.

Table 3. Chemical composition of REOs.

\begin{tabular}{cccccc}
\hline Elements & $\mathrm{Y}_{2} \mathrm{O}_{3}$ & $\mathrm{Eu}_{\mathbf{2}} \mathrm{O}_{3}$ & $\mathrm{Al}_{\mathbf{2}} \mathrm{O}_{3}$ & $\mathrm{SiO}_{2}$ & $\mathrm{Cl}$ \\
\hline Content (\%) & 90.71 & 9.13 & 0.02 & 0.07 & 0.08 \\
\hline
\end{tabular}




\section{Conclusions}

Ammonium chloride roasting, followed by a water leaching process, was proposed and tested to recover $\mathrm{Y}$ and $\mathrm{Eu}$ from waste phosphor in this study. By chlorination roasting at $400{ }^{\circ} \mathrm{C}$ for $2 \mathrm{~h}$ and water leaching, $\mathrm{Y}$ and Eu elements can be efficiently decomposed and extracted into the leach solution. Then, the impurities present in the solution could be removed by adding $\mathrm{NH}_{3} \cdot \mathrm{H}_{2} \mathrm{O}$ and $\mathrm{Na}_{2} \mathrm{~S}$ solution to adjust the $\mathrm{pH}$ to 4.50 . The rare earth elements can be efficiently precipitated after adding the $\mathrm{H}_{2} \mathrm{C}_{2} \mathrm{O}_{4}$ solution at $\mathrm{pH}$ 2. After calcining at $800{ }^{\circ} \mathrm{C}$ for $1 \mathrm{~h}$, the high purity rare earth oxides of $\mathrm{Y}$ and Eu can be obtained.

Compared with the conventional processes, the method used in this study has the advantages of simple operations, low roasting temperatures and low operating costs, and a high recovery of rare earth $(87.35 \%)$ with a high purity of product (99.84\% REOs) can be obtained. The developed process can be potentially implemented in commercial operations, and the obtained rare earth oxides can be reused to synthesize red phosphors directly without separating $\mathrm{Y}_{2} \mathrm{O}_{3}$ and $\mathrm{Eu}_{2} \mathrm{O}_{3}$.

Acknowledgments: This work was financially supported by "Key Projects in the National Science \& Technology Pillar Program during the 12th Five-year Plan Period" (No. 2014BAC03B07), "Key Laboratory for Solid Waste Management and Environment Safety, Ministry of Education of China, Tsinghua University" (No. swmes 2011-03), and "the Fundamental Research Funds for the Central University" (No. WUH165208005)

Author Contributions: Mingming Yu and Shuya Pang conceived and designed the experiments, Mingming Yu performed the experiments; Shuya Pang analyzed the data; Guangjun Mei contributed reagents, materials, and analysis tools; Mingming Yu and Xiaodong Chen wrote the paper.

Conflicts of Interest: The authors declare no conflict of interest.

\section{References}

1. Hirajima, T.; Bissombolo, A.; Sasaki, K.; Nakayama, K.; Hirai, H.; Tsunekawa, M. Floatability of rare earth phosphors from waste fluorescent lamps. Int. J. Miner. Process. 2005, 77, 187-198. [CrossRef]

2. Zhang, W. The development report of China lighting industry in 2011. China Light. Light 2012, 7, 1-4.

3. Tang, Y.B.; Zhu, X.Z.; Wang, H.B.; Qi, F.X. Progress in research on barium magnesium aluminate. Mater. Rev. 2006, 20, 335-338.

4. Wu, Z.H.; Cormack, A.N. Defects in $\mathrm{BaMgAl}_{10} \mathrm{O}_{17}: \mathrm{Eu}^{2+}$ blue phosphor. J. Electroceram. 2003, 10, $179-191$. [CrossRef]

5. Luidold, S.; Poscher, A.; Antrekowitsch, H. Concepts for the extraction of rare earths from spent phosphors. In Proceedings of the 51st Annual Conference of Metallurgists, Niagara Falls, NY, USA, 30 September-3 October 2012.

6. Wu, Y.F.; Yin, X.F.; Zhang, Q.J. The recycling of rare earths from waste tricolor phosphors in fluorescent lamps: A review of processes and technologies. Resour. Conserv. Recycl. 2014, 88, 21-31. [CrossRef]

7. Otsuki, A.; Mei, G.J.; Jiang, Y.R.; Matsuda, M.; Shibayama, A.; Sadaki, J.; Fujita, T. Solid-solid separation of fluorescent powders by liquid-liquid extraction using aqueous and organic phases. Resour. Process. 2006, 3, 121-133. [CrossRef]

8. De Michelis, I.; Ferella, F.; Varelli, E.F.; Veglio, F. Treatment of exhaust fluorescent lamps to recover yttrium: Experimental and process analyses. Waste Manag. 2011, 31, 2559-2568. [CrossRef] [PubMed]

9. Yang, Y.M.; Deng, S.H.; Xie, F.H. Technical study on rare earth from fluorescent powder scrap. Nonferr. Met. Extr. Metall. 2012, 10, 23-26. (In Chinese)

10. Chi, R.A.; Zhang, X.; Zhu, G.; Zhou, Z.A.; Wu, Y.; Wang, C.; Yu, F. Recovery of rare earth from bastnasite by ammonium chloride roasting with fluorine deactivation. Int. J. Miner. Process. 2004, 17, 1037-1043.

11. Ojeda, M.W.; Perino, E.; Ruiz, M.D.C. Gold extraction by chlorination using a pyrometallurgical process. Miner. Eng. 2009, 22, 409-411. [CrossRef]

12. Brocchi, E.A.; Moura, F.J. Chlorination methods applied to recover refractory metals from tin slags. Miner. Eng. 2008, 21, 150-156. [CrossRef]

13. Kuzuya, T.; Hirai, S.; Sokolov, V.V. Recovery of valuable metals from a spent nickel-metal hydride battery: Selective chlorination roasting of an anodic active material with $\mathrm{CCl}_{4}$ gas. Sep. Purif. Technol. 2013, 118, 823-827. [CrossRef] 
14. Yan, Q.X.; LI, X.H.; Wang, Z.X. Extraction of lithium from lepidolite using chlorination roasting-water leaching process. Trans. Nonferr. Met. Soc. China 2012, 22, 1753-1759. [CrossRef]

15. Chi, R.A.; Zhu, G.; Zhou, Z.; Xu, Z. A Novel process for recovering rare earth from weathered black earth. Metall. Mater. Trans. 2000, 31, 191-196. [CrossRef] 